\title{
Large seasonal and diurnal anthropogenic heat flux across four Australian cities
}

\author{
S. Chapman, ${ }^{1}$ J.E.M. Watson, ${ }^{1,2}$ and C.A. McAlpine ${ }^{1}$ \\ ${ }^{1}$ The University of Queensland, School of Geography, Planning and Environmental Management, \\ Brisbane, Australia \\ ${ }^{2}$ Global Conservation Program, Wildlife Conservation Society, New York, USA
}

(Manuscript received June 2016; accepted October 2016)

\begin{abstract}
Anthropogenic heat release is a key component of the urban heat island. However, it is often excluded from studies of the urban heat island because reliable estimates are not available. This omission is important because anthropogenic heat can contribute up to $4^{\circ} \mathrm{C}$ to the urban heat island, and increases heat stress to urban residents. The exclusion of anthropogenic heat means the urban heat island effect on temperatures may be under-estimated. Here we estimate anthropogenic heat for four Australian capital cities (Brisbane, Sydney, Melbourne and Adelaide) to inform the management of the urban heat island in a changing climate. Anthropogenic heat release was calculated using 2011 population census data and an inventory of hourly traffic volume, building electricity and gas use. Melbourne had the highest annual daily average anthropogenic heat emissions, which reached $376 \mathrm{~W} / \mathrm{m}^{2}$ in the city centre during the daytime, while Brisbane's emissions were $261 \mathrm{~W} / \mathrm{m}^{2}$ and Sydney's were $256 \mathrm{~W} / \mathrm{m}^{2}$. Adelaide had the lowest emissions, with a daily average of $39 \mathrm{~W} / \mathrm{m}^{2}$ in the city centre. Emissions varied within and among the four cities and decreased rapidly with distance from the city centre, to $<5 \mathrm{~W} / \mathrm{m}^{2}$ at $20 \mathrm{~km}$ from the city in Brisbane, and $15 \mathrm{~km}$ in Adelaide. The highest emissions were found in the city centres during working hours. The peak emissions reached in the centre of Melbourne are similar to the peak emissions in London and Tokyo, where anthropogenic heat is a large component of the urban heat island. This indicates that anthropogenic heat could be an important contributor to the urban heat island in Australian capital cities, and needs to be considered in climate adaptation studies. This is an important problem because climate change, combined with an ageing population and urban growth, could double the deaths from heatwaves in Australian cities over the next 40 years.
\end{abstract}

\section{Introduction}

Globally, more than half of the world's population lives in cities (United Nations, 2014). In Australia, this proportion is even higher with 66 per cent of the population living in capital cities and by the middle of this century, three quarters of Australians will be living in cities (Australian Bureau of Statistics, 2013b). Energy consumption by urban residents produces anthropogenic heat, which is the energy released from human activity such as traffic, building energy use and human metabolism (Sailor, 2011, Quah and Roth, 2012). This contributes to the urban 'heat island', whereby urban areas are warmer than surrounding rural areas (Sailor, 2011, Kimura and Takahashi, 1991). Anthropogenic heat, by increasing the effect of the urban heat island, also contributes to heat stress, particularly during summer (Bohnenstengel et al., 2014, Luber and McGeehin, 2008, Sharifi et al., 2015). Despite this, anthropogenic heat is often ignored in urban climate studies 
due to a lack of information on city-specific emissions (Quah and Roth, 2012, Sailor, 2011) and for many Australian cities (e.g., Argüeso et al., 2014), anthropogenic heat estimates are simply not available.

The urban heat island increases heat related mortality in cities, particularly during summer (Milojevic et al., 2011). Underestimating the magnitude of the urban heat island effect, therefore, can lead to adverse health outcomes. In the 1980 heatwave in St Louis, deaths were 57 per cent higher in major metropolitan areas than the surrounding countryside (McGeehin and Mirabelli, 2001). The urban heat island also contributed to excess mortality among elderly residents in Paris during the 2003 European heatwave (Laaidi et al., 2012). The elderly and those who live in the top-floors of apartment buildings within inner city areas, and have no air-conditioning or poor building ventilation are particularly vulnerable to heat stress (Luber and McGeehin, 2008, Hajat et al., 2010, Laaidi et al., 2012). Climate change will increase the risk of heat stress, and has been linked to increasing intensity and length of heatwaves in Australian capital cities (Hughes et al., 2016, Hanna et al., 2011). The Climate Council of Australia estimates that climate change, combined with an ageing population and urban growth, could double the deaths from heatwaves in Australian cities over the next 40 years (Hughes et al., 2016), while Bi et al. (2011) report national heat-related deaths could increase by 1250 by 2070 from current levels. The rising risk of heat stress means adaptation and heat-management strategies will become more important, particularly in urban areas (Hughes et al., 2016, Hanna et al., 2011). Excluding important elements of the urban heat island, such as anthropogenic heat, from urban climate studies limits our understanding of Australia's urban climate, and our ability to adapt to rising temperatures.

Previous urban climate studies have neglected anthropogenic heat primarily due to a lack of information on the magnitude of anthropogenic heat flux, as well as difficulty in calculating it (Quah and Roth, 2012, Bohnenstengel et al., 2014). In recent years, however, interest in anthropogenic heat has increased, and inventories have been calculated for some large, densely-populated North American, European and Asian cities (Quah and Roth, 2012, Sailor and Lu, 2004). These studies have shown that the urban anthropogenic heat flux can be large, particularly in highly-populated areas (Quah and Roth, 2012). In London, for example, anthropogenic heat extends the duration of the urban heat island, leading to high temperatures persisting throughout the evening, as well as increasing temperatures by over $1^{\circ} \mathrm{C}$ (Bohnenstengel et al., 2014). In Tokyo, most of the nocturnal urban heat island of $2-3^{\circ} \mathrm{C}$ has been attributed to anthropogenic heat (Kimura and Takahashi, 1991). A similar result has been found for Philadelphia in winter, where anthropogenic heating increases urban temperatures by $2.5^{\circ} \mathrm{C}$ (Fan and Sailor, 2005).

Anthropogenic heat emissions result from energy consumption in cities from electricity and gas use, with their magnitude varying according to climatic conditions, per capita energy use and population density (Sailor, 2011, Quah and Roth, 2012, Oke, 1988). Per capita energy consumption is linked to the amount and type of industry in the city, urban transportation (especially traffic volume), and the amount of energy used by urban residents (Oke, 1988). The spatial distribution of the urban population also affects anthropogenic heat emissions, with higher emissions found in more densely populated areas (Quah and Roth, 2012, Oke, 1988). In higher latitude regions such as Europe, Japan, northern USA and Canada, higher anthropogenic heat intensities occur in winter, due to heating requirements (Wienert and Kuttler, 2005, Taha, 1997). In Philadelphia, the contribution of anthropogenic heat to night-time air temperature varies between $0.8{ }^{\circ} \mathrm{C}$ in summer and $2.5^{\circ} \mathrm{C}$ in winter (Fan and Sailor, 2005). There has been less work on anthropogenic heat emissions in the tropics (Quah and Roth, 2012). In these regions, the seasonal evolution of anthropogenic heat emissions depends on whether heating or cooling is used. In São Paulo, seasonal variation was generally unimportant due to the lack of air-conditioning and heating (Ferreira et al., 2011), while in Singapore higher emissions occurred in summer due to the need for cooling (Quah and Roth, 2012).

Three main methods are used to calculate anthropogenic heat emissions: inventory, micro-meteorological, and buildingenergy models (Sailor, 2011). The inventory method is the most commonly used and is based on energy consumption data (Sailor, 2011, Quah and Roth, 2012). However, it does not account for environmental loads and does not partition energy into sensible and latent heat (Sailor, 2011). It also neglects the time lag between energy use and heat emission which occurs due to storage of heat within buildings (Sailor, 2011, Dhakal et al., 2003). Micro-meteorological approaches are based on energy-budget closure methods and enable targeted estimation at the neighbourhood level (Sailor, 2011). However, these methods often cannot produce reliable diurnal profiles of heat release due to problems differentiating between sources of heat and large errors in estimating sensible and latent heat fluxes (Sailor, 2011). The third method is to use building energy models. These models ignore emissions from other sources and so must be used in conjunction with inventory methods when estimating anthropogenic heat emissions across a city (Sailor, 2011). However, the data require- 
ments for parameterising building models can be quite large (Sailor, 2011). Despite the limitations of the inventory method, it remains the preferred approach to estimate anthropogenic heat in cities (Sailor, 2011, Quah and Roth, 2012).

City-specific anthropogenic heat estimates are necessary to understand how emissions impact on urban temperatures in individual cities (Quah and Roth, 2012, Bohnenstengel et al., 2014). However, few Australian cities have anthropogenic heat estimates. The most recent for Brisbane and Sydney were in 2001 and 1971 respectively, and observations were made for Preston, Melbourne in 2007 (Khan and Simpson, 2001, Quah and Roth, 2012, Coutts et al., 2007). Anthropogenic heat was also recently estimated for Sydney by Sailor et al. (2015), however this was based on an equation developed for American cities. No previous calculations are available for Adelaide. This lack of information means anthropogenic heat is largely excluded from urban climate studies for Australian cities, which could lead to an underestimation of the urban heat island effect under the current and future climate regimes.

The aim of this study was to address this gap by calculating seasonal and diurnal anthropogenic emissions in Brisbane, Sydney, Melbourne and Adelaide. Sydney is Australia's largest capital and climate change is expected to increase heat related mortality by over 300 per cent by 2050 (Bi et al., 2011). Melbourne and Adelaide were selected as they experience some of the most severe heat waves in Australia (Cowan et al., 2014, Black et al., 2015). In the last 30 years, Adelaide has experienced an increase of $4.3^{\circ} \mathrm{C}$ in the intensity of the hottest heatwave days (Hughes et al., 2016). The next largest increase of $2^{\circ} \mathrm{C}$ has been in Melbourne (Hughes et al., 2016). Brisbane was selected as it is the third-largest city in Australia, and regularly experiences high summer temperatures (Hondula and Barnett, 2014). Populations of the four cities are expected to face increased heat stress due to temperature increases from climate change (Bi et al., 2011).

\section{Methods and data}

\subsection{Study cities}

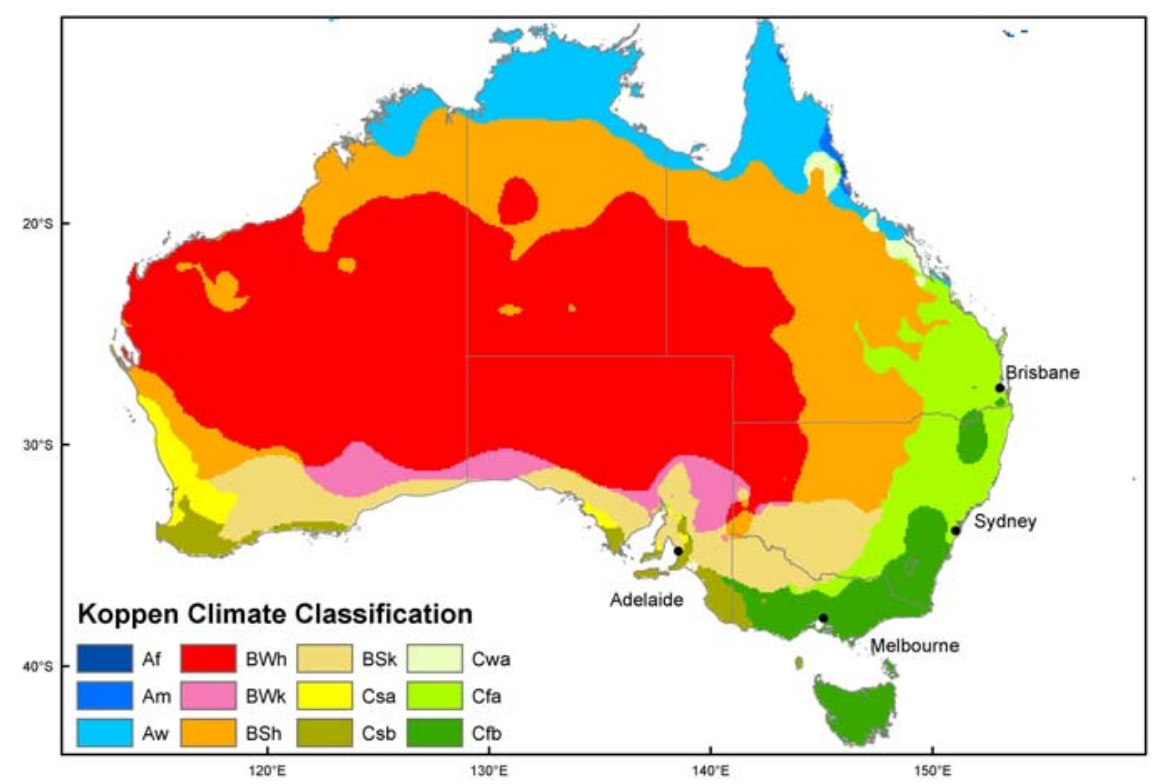

Figure 1 Koppen climate classification of Australia (Peel et al., 2007), with location of study cities. Af = Tropical rainforest, $\mathrm{Am}=$ Tropical monsoon, $\mathrm{Aw}=$ Tropical savanna, $\mathrm{BWh}=$ Arid hot desert, $\mathrm{BWk}=$ Arid cold desert, $\mathrm{BSh}=$ Arid hot steppe, BSk = Arid cold steppe, Csa = Temperate dry, hot summer, Csa = Temperate dry, warm summer, Cwa = Temperate dry winter, hot summer, Cfa = Temperate, no dry season, hot summer, $\mathrm{Cfb}=$ Temperate, no dry season, warm summer.

Brisbane (see Figure 1) has a subtropical climate with a warm, humid summer with a low winter rainfall (Bureau of Meteorology, 2012). In 2015, Brisbane’s population was 2.31 million (Australian Bureau of Statistics, 2015a). The inner city suburbs of New Farm (6,500 people km${ }^{-1}$ ), Kangaroo Point (6,400 people km $)$ and Highgate Hill (5,500 people km are the most densely populated areas (Table 1). 
Sydney has a temperature climate, and rainfall is similar in summer and winter (Bureau of Meteorology, 2012). In 2015 Sydney had a population of 4.92 million people (Australian Bureau of Statistics, 2015a). The most densely populated area was Pyrmont-Ultimo, with 15,100 people km¹ (Australian Bureau of Statistics, 2015a).

Melbourne has a temperate climate, with a similar rainfall in summer and winter (Bureau of Meteorology, 2012). In 2015, Melbourne's estimated population was 4.53 million (Australian Bureau of Statistics, 2015a). The most densely populated area is the inner-city, with a population density of 14,100 people km-1 (Australian Bureau of Statistics, 2015a).

Adelaide has a temperate climate, with wet winters and low summer rainfall (Bureau of Meteorology, 2012). Adelaide’s population was 1.32 million in 2015, which is 78 per cent of South Australia's population (Australian Bureau of Statistics, 2013a). The most densely populated suburb is Unley - Parkside, with 3,000 people km-1 (Australian Bureau of Statistics, 2015a).

\begin{tabular}{|c|c|c|c|c|c|c|c|}
\hline City & $\begin{array}{l}\text { Mean } \\
\text { monthly } \\
\text { minima } \\
\text { range }\left({ }^{\circ} \mathrm{C}\right)\end{array}$ & $\begin{array}{l}\text { Mean } \\
\text { monthly } \\
\text { maxima } \\
\text { range }\left({ }^{\circ} \mathrm{C}\right)\end{array}$ & $\begin{array}{l}\text { Annual av- } \\
\text { erage rain- } \\
\text { fall }(\mathrm{mm})\end{array}$ & $\begin{array}{l}\text { Average popula- } \\
\text { tion density } \\
\left(\text { people } \mathrm{km}^{-1}\right)\end{array}$ & $\begin{array}{l}\text { Maximum рори- } \\
\text { lation density } \\
\left.\text { (people } \mathrm{km}^{-1}\right)\end{array}$ & $H D D$ & $C D D$ \\
\hline Brisbane & $\begin{array}{l}10.0- \\
20.9\end{array}$ & $20.6-29.1$ & $1,186.2$ & 150 & 6,500 & 232 & 1228 \\
\hline Sydney & $8.1-18.8$ & $16.3-25.9$ & $1,214.6$ & 400 & 15,100 & 743 & 556 \\
\hline Melbourne & $5.4-14.2$ & $13.1-26.6$ & 534.5 & 450 & 14,100 & 1423 & 244 \\
\hline Adelaide & $7.5-17.2$ & $15.3-29.5$ & 540.9 & 400 & 3,000 & 1007 & 584 \\
\hline
\end{tabular}

Table 1 Summary of the climate and population of the study cities. HDD (heating degree days) and CDD (cooling degree days) used a base temperature of $18^{\circ} \mathrm{C}$ (Guan, 2009). Most densely populated suburbs are New Farm in Brisbane, Pyrmont-Ultimo in Sydney, Melbourne Central Business District (CBD) and Unley - Parkside in Adelaide (Bureau of Meteorology, 2016a, Bureau of Meteorology, 2012, Bureau of Meteorology, 2016c, Bureau of Meteorology, 2016b, Australian Bureau of Statistics, 2015a).

\subsection{Anthropogenic heat calculations}

Anthropogenic heat, $Q_{f}$, is a component of the urban energy balance (Quah and Roth, 2012):

$$
Q^{*}+Q_{f}=Q_{H}+Q_{E}+\Delta Q_{S}+\Delta Q_{A}
$$

where $\mathrm{Q}^{*}$ is the net all-wave radiation, $\mathrm{Q}_{\mathrm{H}}$ is sensible heat flux, $\mathrm{Q}_{\mathrm{E}}$ is latent heat flux, $\mathrm{Q}_{\mathrm{s}}$ is storage and $\mathrm{Q}_{\mathrm{a}}$ is net advective heat flux. $\mathrm{Q}_{\mathrm{f}}$ can be broken down into the sum of waste heat from traffic, $\mathrm{Q}_{\mathrm{v}}$, buildings, $\mathrm{Q}_{\mathrm{b}}$, and human metabolism, $\mathrm{Q}_{\mathrm{h}}$ (Sailor and Lu, 2004):

$$
Q_{f}=Q_{v}+Q_{b}+Q_{h}
$$

Equation 2 was applied to each Statistical Area-2 (SA2) census region within the Brisbane, Sydney, Melbourne (excluding Mornington Peninsula) and Adelaide urban areas, and was based on Sailor and Lu (2004). The code was implemented using $\mathrm{R}$ (R Core Team, 2015). For each city, the components of $\mathrm{Q}_{\mathrm{f}}$ were determined using an inventory approach. This required data (Table 2) on vehicle usage, building electricity and gas use and population density (Sailor and Lu, 2004). Temporal variation in $Q_{f}$ was based on hourly variation in population density and emission profiles for each component of $Q_{f}$ (Sailor and $\mathrm{Lu}, 2004)$. Seasonal variation in $\mathrm{Q}_{\mathrm{f}}$ was based on variation in electricity and gas usage throughout the year.

The spatial variation in $\mathrm{Q}_{\mathrm{f}}$ was calculated using population density data (working and resident populations) available for the Statistical Area - Level 2 (SA2) regions (Australian Bureau of Statistics, 2011a). The SA2 regions were used to define 
the boundary of the city, and all SA2 regions within Greater Brisbane, Greater Melbourne (excluding Mornington), Greater Sydney and Greater Adelaide were used. Statistical areas vary in size and have, on average, a population of 10,000 (Australian Bureau of Statistics, 2011a). In the Greater Brisbane area, the average size of SA2s is $11 \mathrm{~km}^{2}$ (range 1 - 490 $\mathrm{km}^{2}$ ), while in Sydney the average size is $43 \mathrm{~km}^{2}$ (range $1-2458 \mathrm{~km}^{2}$ ). The high maximum size for Greater Sydney is due to the large size of the Blue Mountains South area. In Melbourne, the average size of SA2s is $34 \mathrm{~km}^{2}\left(\mathrm{range} 1-728 \mathrm{~km}^{2}\right)$ and in Adelaide the average is $30 \mathrm{~km}^{2}$ (range $1-395 \mathrm{~km}^{2}$ ).

\begin{tabular}{|c|c|c|}
\hline Data & Description & Source \\
\hline \multicolumn{3}{|l|}{ Population density } \\
\hline $\begin{array}{l}\text { Day/night popula- } \\
\text { tion }\end{array}$ & $\begin{array}{l}\text { Resident and working populations, including } \\
\text { percent employed residents. }\end{array}$ & $\begin{array}{l}2011 \text { census, available at SA2 level } \\
\text { (2011b). }\end{array}$ \\
\hline $\begin{array}{l}\text { Area of SA2 re- } \\
\text { gions }\left(\mathrm{m}^{2}\right)\end{array}$ & $\begin{array}{l}\text { Area of Statistical Area - Level } 2 \text { regions. } \\
\text { Used to calculate population density. }\end{array}$ & $\begin{array}{l}\text { Extracted from SA2 shapefiles, } \\
\text { available from ABS (2011c). }\end{array}$ \\
\hline \multicolumn{3}{|l|}{ Vehicle emissions } \\
\hline $\begin{array}{l}\text { Hourly traffic } \\
\text { counts }\end{array}$ & $\begin{array}{l}\text { Used to develop diurnal traffic profile. Mel- } \\
\text { bourne data was used for Adelaide due to a } \\
\text { lack of data. }\end{array}$ & $\begin{array}{l}\text { Available from VicRoads (2015) for } \\
\text { Melbourne, Roads and Maritime } \\
\text { Service (2015) for Sydney and } \\
\text { Brisbane City Council (2015). }\end{array}$ \\
\hline Car travel $(\mathrm{km})$ & Average km travelled in a year per car. & $\begin{array}{l}\text { Available from ABS for each state } \\
\text { (2012b). }\end{array}$ \\
\hline $\begin{array}{l}\text { Fuel economy } \\
(\mathrm{km} / \mathrm{L})\end{array}$ & Average fuel economy. & Available from ABS (2012b). \\
\hline Car use & $\begin{array}{l}\text { Percentage of people who travel to work using } \\
\text { cars. }\end{array}$ & $\begin{array}{l}\text { From published literature and gov- } \\
\text { ernment reports (de Silva and } \\
\text { Lightfoot, 2010, Department of } \\
\text { Infrastructure and Transport, 2013). }\end{array}$ \\
\hline $\begin{array}{l}\text { Calorific values of } \\
\text { fuel }(\mathrm{J} / \mathrm{kg})\end{array}$ & $\begin{array}{l}\text { Quantity of heat produced by combustion of } \\
\text { fuel. }\end{array}$ & $\begin{array}{l}\text { Used values from Quah and Roth } \\
\text { (2012). }\end{array}$ \\
\hline Fuel density $(\mathrm{kg} / \mathrm{L})$ & $\begin{array}{l}\text { Fuel density, used in conjunction with calorif- } \\
\text { ic value of fuel, is used to calculate energy } \\
\text { released by fuel. }\end{array}$ & $\begin{array}{l}\text { Used values from Quah and Roth } \\
\text { (2012). }\end{array}$ \\
\hline \multicolumn{3}{|l|}{ Building emissions } \\
\hline $\begin{array}{l}\text { Energy consump- } \\
\text { tion }\end{array}$ & $\begin{array}{l}\text { Consumption of heating fuels and electricity. } \\
\text { Available only at national level. Distributed } \\
\text { among states based on state energy use frac- } \\
\text { tions. }\end{array}$ & $\begin{array}{l}\text { Available from ABS at national level } \\
\text { (Australian Bureau of Statistics, } \\
\text { 2015b, Bureau of Resources and } \\
\text { Energy Economics, 2014a). }\end{array}$ \\
\hline $\begin{array}{l}\text { Hourly electricity } \\
\text { usage }\end{array}$ & Diurnal profile of electricity use. & $\begin{array}{l}\text { Available half-hourly (Australian } \\
\text { Energy Market Operator, 2015b). }\end{array}$ \\
\hline Monthly gas usage & $\begin{array}{l}\text { Used to develop summer and winter profiles } \\
\text { of gas usage. }\end{array}$ & $\begin{array}{l}\text { AEMO actual flow data (Australian } \\
\text { Energy Market Operator, 2015a). }\end{array}$ \\
\hline Hourly gas usage & $\begin{array}{l}\text { Variation in gas usage throughout the day. } \\
\text { Only available for Melbourne. }\end{array}$ & Estimated based on Palmer (2012). \\
\hline State population & Used to calculate per capita energy use. & Available from ABS (2012a). \\
\hline
\end{tabular}

Table 2 Data used in calculation of each element of anthropogenic heat emissions. 
Data availability is a common limitation to anthropogenic heat studies (Quah and Roth, 2012). Our approach is similar to Quah and Roth (2012) and Sailor and Lu (2004). These studies had similar issues with data availability, and used a combination of bottom-up and top-down approaches to estimate the components of $\mathrm{Q}_{\mathrm{f}}$. The bottom-up approach aggregated small-scale data to estimate up to the level of interest, for example, using 30-min electricity data to develop an hourly profile of electricity usage (Quah and Roth, 2012). The top-down approach uses data at larger scales and then downscales it, for example by turning total state electricity or gas usage into per capita electricity use using population data (Quah and Roth, 2012). This combined approach was necessary as much of the required data was only available at the state level. Data availability for each component of $\mathrm{Q}_{\mathrm{f}}$ will be discussed in more detail in the following sections.

\subsection{Population density}

The spatial and hourly distribution of anthropogenic heat emissions varies with the population density of the respective city and statistical area. Estimates of hourly variation in population density were based on the working and resident population densities, which are available for the respective statistical areas. Daytime and night-time population densities were calculated based on Sailor and Lu (2004) as:

$$
\rho_{\text {day }}=(\mathrm{NWRP}+\mathrm{WP}) / \mathrm{A}
$$

Where NWRP is the non-working resident population, WP is the working population and A is the area of the SA2 region. These data were available for each SA2 region. Night-time population was taken to be the same as the resident population, as per Sailor and Lu (2004). The hours used for day-time (or working hours) were 0800 - 1600, and the hours used for night-time were $1800-0600$. As there is no data available on specific working hours, $0800-1600$ was used as the working time for the entire working population (Sailor and Lu, 2004). Shoppers and tourists were not included due to a lack of data.

All four cities have a large variation in night-time and day-time population densities (Figure 2). For this study, the city centre was defined as the SA2 region with the highest daytime population density. The size of the city centre SA2 region is 2.2, 4.3, 2.4 and $10.48 \mathrm{~km}^{2}$ for Brisbane, Sydney, Melbourne and Adelaide respectively. During the day, there is a large increase in population density in the city centres due to the large influx of CBD workers. In contrast, the low population densities in the city centres at night time reflect the small resident populations.

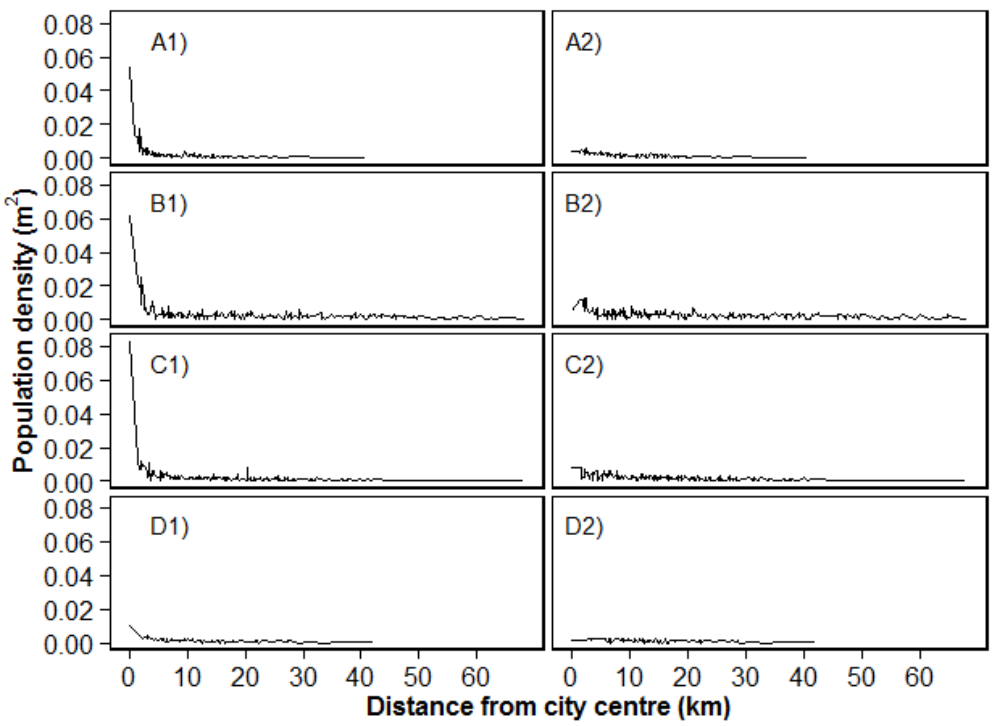

Figure 2 Day-time $=1$, (0800 - 1600 hours $)$, and night-time = 2, (1800 - 0600 hours), population densities for SA2 census regions within $70 \mathrm{~km}$ of city centre for A) Brisbane, B) Sydney, C) Melbourne, and D) Adelaide. The city centres experience a large influx in workers during the day, and have lower night-time resident populations. 


\section{$2.4 \quad$ Vehicle traffic}

Emissions from vehicle traffic, $\mathrm{Q}_{\mathrm{v}}$, were calculated using the following equation (Sailor and Lu, 2004):

$$
Q_{v}(\mathrm{~h})=T \times E \times V \times F_{t}(h)
$$

where $\mathrm{T}=$ distanced travelled per vehicle, $\mathrm{E}=$ energy released per $\mathrm{km}$ travelled $(\mathrm{J} / \mathrm{km}), \mathrm{V}=$ number of vehicles, and $F_{t}(h)$ is the fractional traffic profile.

E, the energy release per km travelled, was calculated based on the calorific value of fuel, fuel density and average fuel economy (Quah and Roth, 2012, Australian Bureau of Statistics, 2012b). V was calculated based on population density, and the percentage of population that use cars to commute to work (de Silva and Lightfoot, 2010, Department of Infrastructure and Transport, 2013). This was 90 per cent for all three cities. T, the distance travelled per vehicle, was calculated based on state travel data (Australian Bureau of Statistics, 2012), and $F_{t}(h)$ was available from Brisbane City Council, VicRoads (2015) for Melbourne, and the Roads and Maritime Service (2015) for Sydney. For Brisbane, traffic volume data was available for the intersection of Ann and Edward St in the city centre. Hourly variation in traffic was not available for Adelaide. The Brisbane, Sydney and traffic profiles (Figure 3) are very similar to profiles for other urban centres in Europe and the USA (Sailor and Lu, 2004, Hallenbeck et al., 1997, Menut et al., 2012), as well as a general Australian urban profile (Bureau of Transport and Regional Economics, 2007). The Melbourne profile was used for Adelaide as it is the most similar to the general Australian urban profile. This does not alter the daily magnitude of vehicle emissions for Adelaide, but it could affect the distribution of hourly emissions if there are large differences in traffic profiles among the cities.

No seasonal profile was calculated for vehicle emissions as studies in Melbourne (Keay and Simmonds, 2005) and the USA have found there is only minor seasonal variation in vehicle usage, particularly in urban areas (Sailor and Lu, 2004, Hallenbeck et al., 1997).
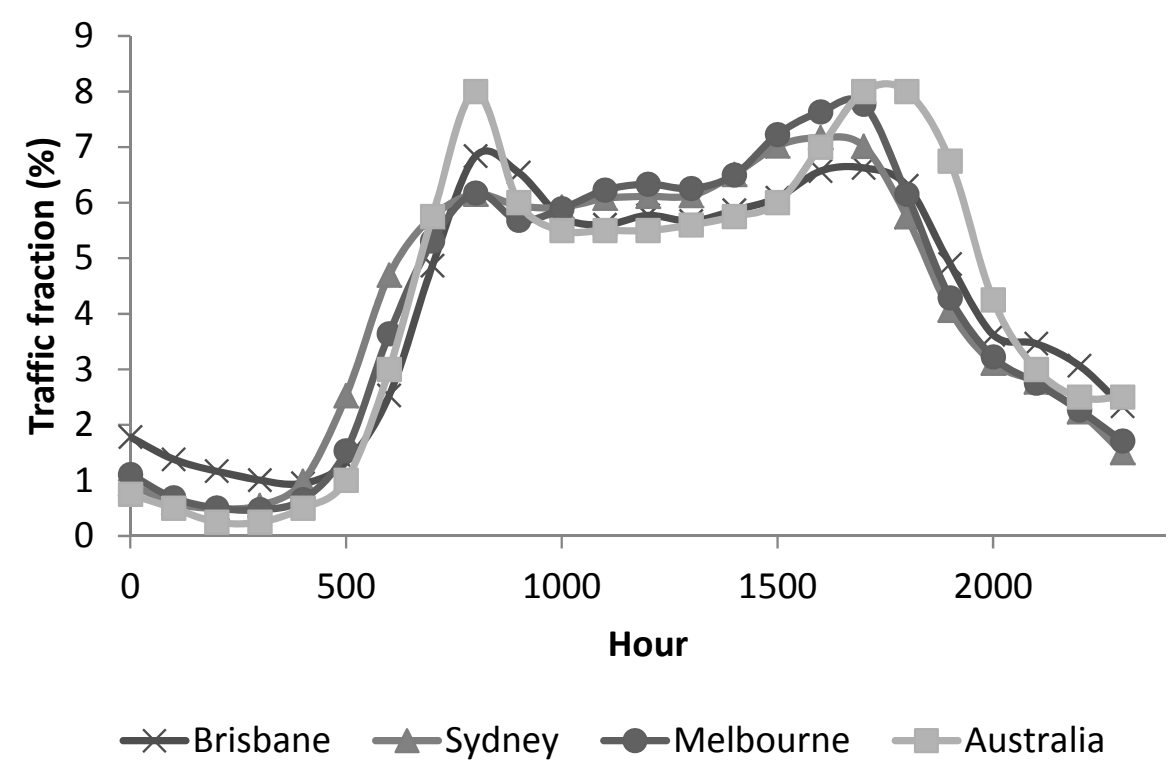

Figure 3 Hourly traffic fraction for Brisbane, Sydney, Melbourne and the overall Australian metropolitan average. Melbourne data was sourced from VicRoads (2015), Sydney data was sourced from the Roads and Maritime Service (2015) and Brisbane data from Brisbane City Council (2015). Australian metropolitan average data estimated were derived from Bureau of Transport and Regional Economics (2007). All profiles show peaks at 0800 and 1600 hours associated with people driving to and from work. 


\subsection{Building emissions}

Energy emissions from buildings result from heating, cooling, ventilation, lighting and use of appliances (Sailor and Lu, 2004, Quah and Roth, 2012). There is a time lag between energy consumption and heat emission, which varies according to building design, ventilation, insulation and the type of cooling/heating system in place (Sailor and Lu, 2004, Quah and Roth, 2012). Due to the complexities and data required to estimate the lag between energy consumption and heat release, it was not calculated, and energy release was assumed to occur at the same time as energy consumption. This assumption is common to most anthropogenic heat estimates which adopt the inventory method (Sailor and Lu, 2004, Quah and Roth, 2012).

Building emissions, $\mathrm{Q}_{\mathrm{b}}$, were broken down into heat released from electricity and heating fuel usage. National electricity data were split among states based on state energy use fractions (Bureau of Resources and Energy Economics, 2014a). The Bureau of Resources and Energy Economics (BREE) calculates national electricity data and state energy use fractions based on data from the National Greenhouse and Energy Reporting Scheme, federal and state government agencies and public company reporting (Bureau of Resources and Energy Economics, 2014b). State electricity use was then transformed into per capita energy use. This included industrial energy use, excluding agricultural and mining electricity use on the assumption that these industries would be occurring mainly in rural areas. Data on hourly electricity use data were available from the Australian Energy Market Operator (2015b) and were used to develop diurnal profiles (Figure 4). All four cities have similar electricity usage profiles, with morning and afternoon peaks, which are particularly pronounced in winter. In summer, the peak is less pronounced. In Brisbane, Sydney and Melbourne, summer electricity use increases throughout the day. In Adelaide, during summer, there is a slight decrease in electricity usage between the morning and afternoon peaks. In winter, for all four cities, there is a morning and afternoon peak in electricity usage and a trough in the middle of the day.

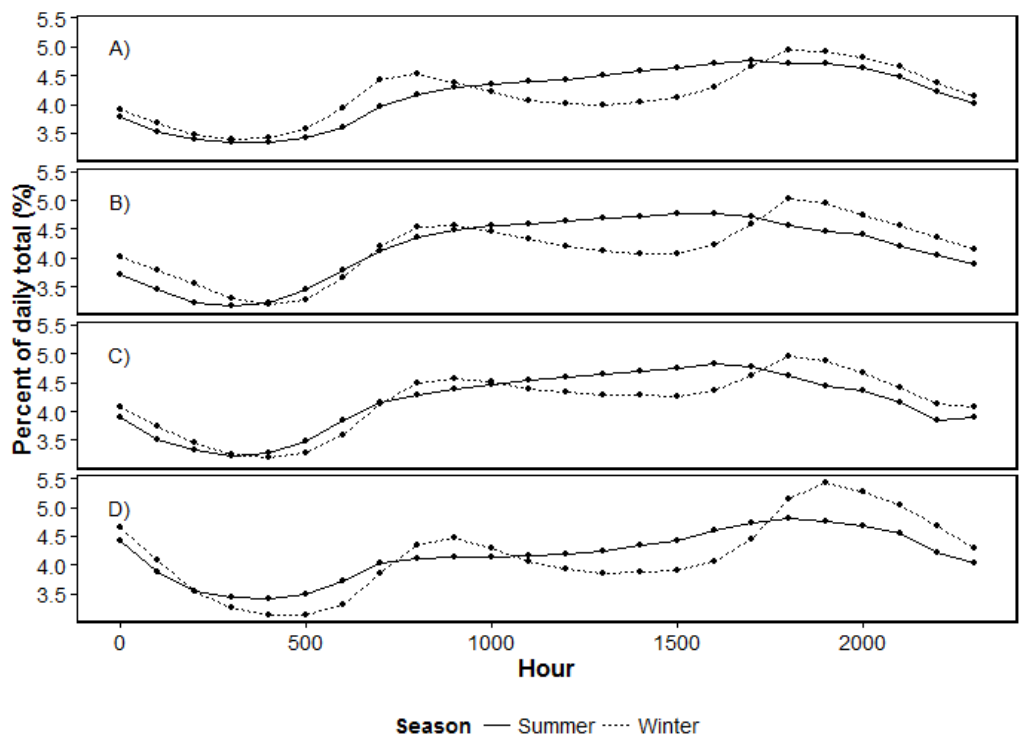

Figure 4 Hourly electricity profiles for A) Brisbane, B) Sydney C) Melbourne and D) Adelaide in summer and winter (Australian Energy Market Operator, 2015b). Summer electricity use increases throughout the day and decreases after 1800 hours. Winter electricity usage has two peaks, at 0900 and 1900 hours.

Heat release from gas was calculated using Equation 4 (Sailor and Lu, 2004):

$$
Q_{b g}(\mathrm{~h})=G \times C_{g a s} \times F_{g}(h) \times \rho_{\text {pop }}(h)
$$

where $G$ = daily gas consumption per person, $C_{g a s}=$ combustion efficiency of gas, and $F_{g}(h)=$ hourly fractional profile of gas consumption. Daily gas data were available for all cities from the Australian Energy Market Operator (2015a). Hourly data was more difficult to obtain, which is a common issue in anthropogenic heat studies (Sailor and Lu, 2004). Previous 
work suggests that heating fuel usage is related to temperature in winter, but not in summer (Sailor and Lu, 2004). For this reason, and due to difficulty acquiring hourly data, summer heating fuel usage was assumed to be uniform throughout the day, as per Sailor and Lu (2004).

An hourly profile of gas usage in July is available for Melbourne, and was used as the winter profile (Palmer, 2012). The Melbourne winter profile increases during the day until 0700 hours when it peaks. It then decreases until 1200 hours, before increasing and peaking again at 1800 hours. No profiles were available for Brisbane, Adelaide or Sydney, and so the Melbourne winter profile was used. As with the hourly vehicle profile, using the Melbourne profile does not change the daily magnitude of emissions, however it may result in the miss-timing of the hourly emissions if the profile is substantially different. Other studies have excluded emissions from gas altogether (e.g., Quah and Roth, 2012), or linked emissions to hourly variations in temperatures (e.g., Sailor and Lu, 2004). However, this was not feasible in this study due to a lack of city-specific information on how gas usage varies with temperature.

\subsection{Human metabolism}

To estimate heat release from human metabolism, it is necessary to quantify how metabolic rates vary throughout the day (Sailor and Lu, 2004). Previous work has found the sleeping rate for $70 \mathrm{~kg}$ males to be $75 \mathrm{~W}$, which increases during the day depending on activity (Sailor and Lu, 2004). A person sitting has a metabolic rate of around $115 \mathrm{~W}$, which increases to $230 \mathrm{~W}$ for slow walking (Sailor and Lu, 2004). Strenuous activities have rates around $300 \mathrm{~W}$ (Sailor and Lu, 2004). For this study, the sleeping rate (2300 - 0500 hours) was taken to be $75 \mathrm{~W} /$ person, and the active rate $(0700$ - 2100 hours) was taken to be $175 \mathrm{~W} /$ person. The transition period was the average of the sleeping and waking rate. These rates are the same as those used by Sailor and Lu (2004) for American cities and Allen et al. (2011) in their global study, and similar to rates used in other studies (Quah and Roth, 2012, Smith et al., 2009).

\section{Results}

We found annual city-wide daily maxima in anthropogenic heat at 0800 hours in Brisbane of $3.7 \mathrm{~W} / \mathrm{m}^{2}$, and 1700 hours in Sydney, Melbourne and Adelaide of $1.8 \mathrm{~W} / \mathrm{m}^{2}, 2.0 \mathrm{~W} / \mathrm{m}^{2}$ and $1.6 \mathrm{~W} / \mathrm{m}^{2}$ respectively. Average annual daily minima were reached in the early morning hours for Brisbane, Sydney, Melbourne and Adelaide $\left(1.7 \mathrm{~W} / \mathrm{m}^{2}, 0400\right.$ hours; $0.6 \mathrm{~W} / \mathrm{m}^{2}$, 0300 hours; $0.8 \mathrm{~W} / \mathrm{m}^{2}$, 0300 hours; $0.6 \mathrm{~W} / \mathrm{m}^{2}, 0300$ hours, respectively).

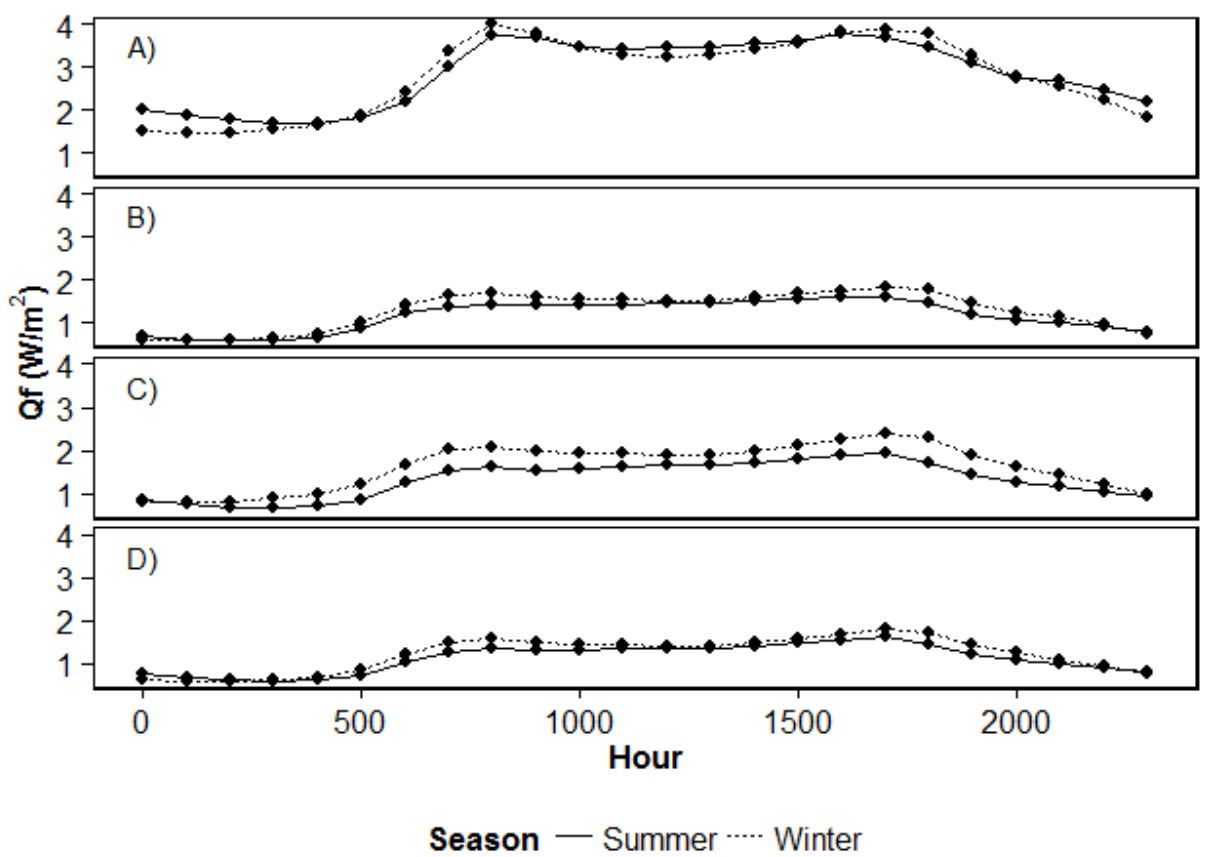


Figure 5 Average hourly anthropogenic heat flux $\left(\mathrm{W} / \mathrm{m}^{2}\right)$ for A) Brisbane, B) Sydney, C) Melbourne and D) Adelaide in summer and winter.

The anthropogenic heat fluxes for each city varied with season (Figure 5). Sydney, Melbourne and Adelaide had higher average daily anthropogenic heat fluxes in winter $\left(1.3 \mathrm{~W} / \mathrm{m}^{2}, 1.6 \mathrm{~W} / \mathrm{m}^{2}, 1.2 \mathrm{~W} / \mathrm{m}^{2}\right.$, respectively) than in summer $(1.2$ $\mathrm{W} / \mathrm{m}^{2}, 1.3 \mathrm{~W} / \mathrm{m}^{2}, 1.1 \mathrm{~W} / \mathrm{m}^{2}$ respectively). In Adelaide, the heat flux in the early morning hours $(0100-0200)$ was higher in summer than in winter. Conversely, Brisbane had a higher average heat flux in summer than in winter, although the difference was only $0.04 \mathrm{~W} / \mathrm{m}^{2}$. These differences are mainly driven by differences in heating fuel and electricity usage in winter and summer. Thirty percent of Sydney's annual gas usage is in winter, while 20 per cent is in summer. The difference in summer and winter gas use is even more pronounced in Melbourne, with 40 per cent in winter and 17 per cent in summer. Adelaide also has a higher gas use in winter (34 per cent of the annual total), than in summer (24 per cent of the annual total). In contrast, Brisbane's winter gas usage was only 2 percent higher than in summer, while electricity use was 9 per cent higher in summer than in winter.

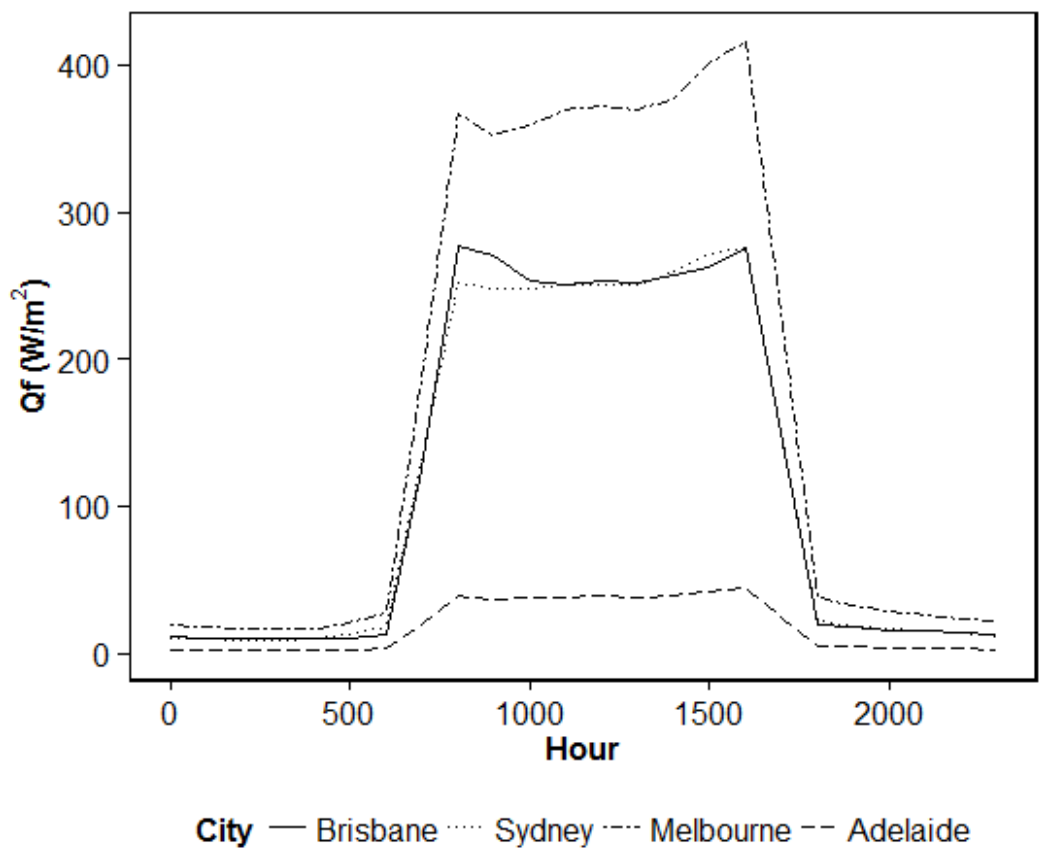

Figure 6 Diurnal variation in non-seasonal total anthropogenic heat $\left(\mathrm{Q}_{\mathrm{f}}\right)$ for the respective city centres. The Statistical Area - 2 Region chosen for each city was A) Brisbane City (2.2), B) Sydney - Haymarket - The Rocks (4.3), C) Melbourne (2.4) and D) Adelaide (10.48). Area in $\mathrm{km}^{2}$ in brackets.

As expected, anthropogenic heat emissions were higher in the city centres than the surrounding SA2 regions for all cities (Figure 7). Daily annual (non-seasonal) average anthropogenic heat emissions were $261 \mathrm{~W} / \mathrm{m}^{2}, 256 \mathrm{~W} / \mathrm{m}^{2}, 376 \mathrm{~W} / \mathrm{m}^{2}$ and $39 \mathrm{~W} / \mathrm{m}^{2}$ for the city centres of Brisbane, Sydney, Melbourne, and Adelaide respectively, which have an area of $2.2 \mathrm{~km}{ }^{2}$, $4.3 \mathrm{~km}^{2}, 2.4 \mathrm{~km}^{2}$ and $10.48 \mathrm{~km}^{2}$, respectively. The highest heat flux occurred at 1600 hours in in all cities (Figure 6). The peak for the Brisbane CBD was $281 \mathrm{~W} / \mathrm{m}^{2}$ in summer and $284 \mathrm{~W} / \mathrm{m}^{2}$ in winter. Sydney's peak occurred in the Haymarket - Rocks SA2 region, and was $270 \mathrm{~W} / \mathrm{m}^{2}$ in summer and $297 \mathrm{~W} / \mathrm{m}^{2}$ in winter. For the Melbourne CBD, the peak heat flux was $400 \mathrm{~W} / \mathrm{m}^{2}$ in summer and $480 \mathrm{~W} / \mathrm{m}^{2}$ in winter. Adelaide peaked at $45 \mathrm{~W} / \mathrm{m}^{2}$ in summer and $48 \mathrm{~W} / \mathrm{m}^{2}$ in winter. 

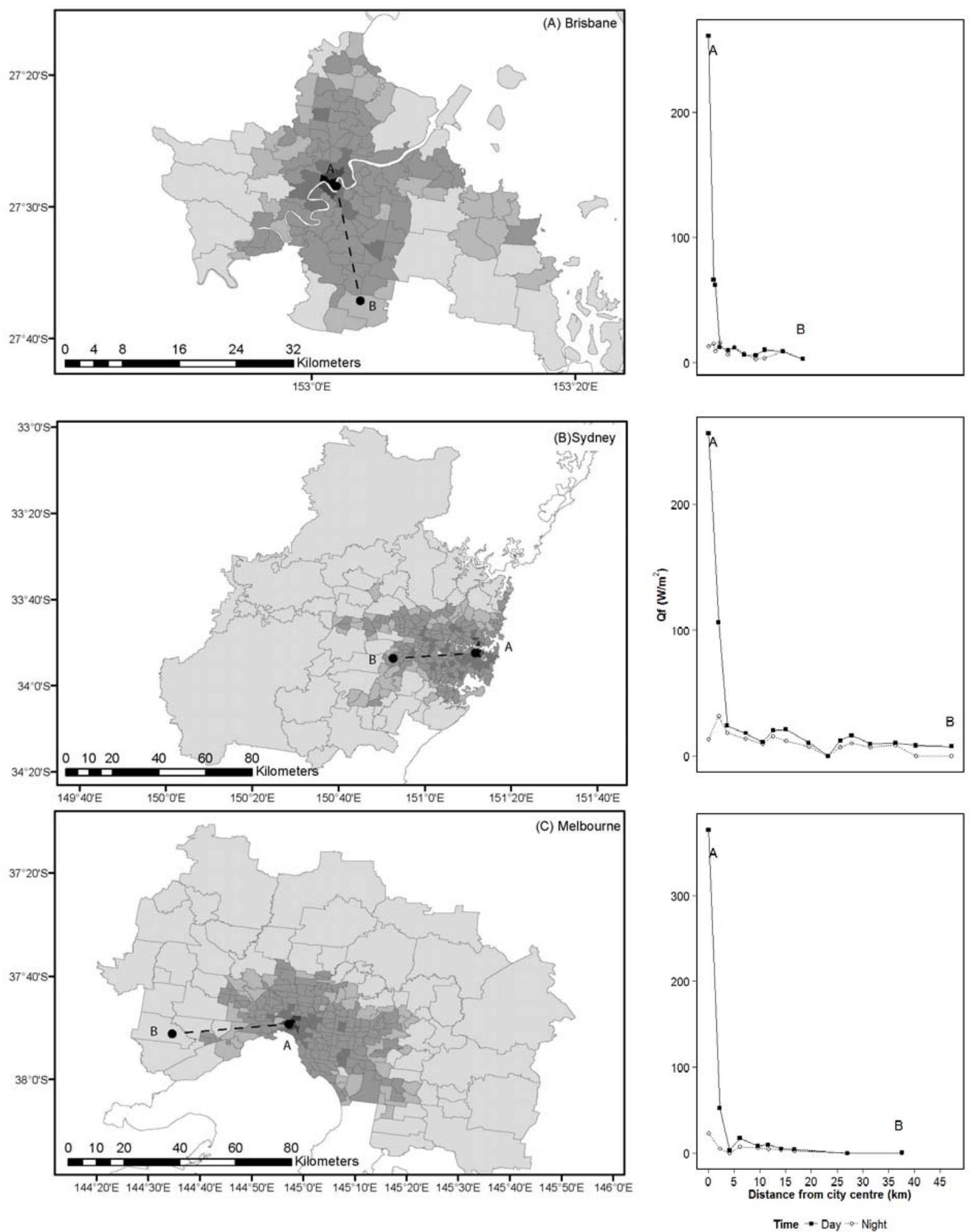

Qf $\left(W / m^{2}\right)$ $0.0 \cdot 2.0 \square \square$
$2.1 \cdot 5.5 \square$
5 $40.1 \cdot 85.0$ $85.1 \cdot 380.0$ 

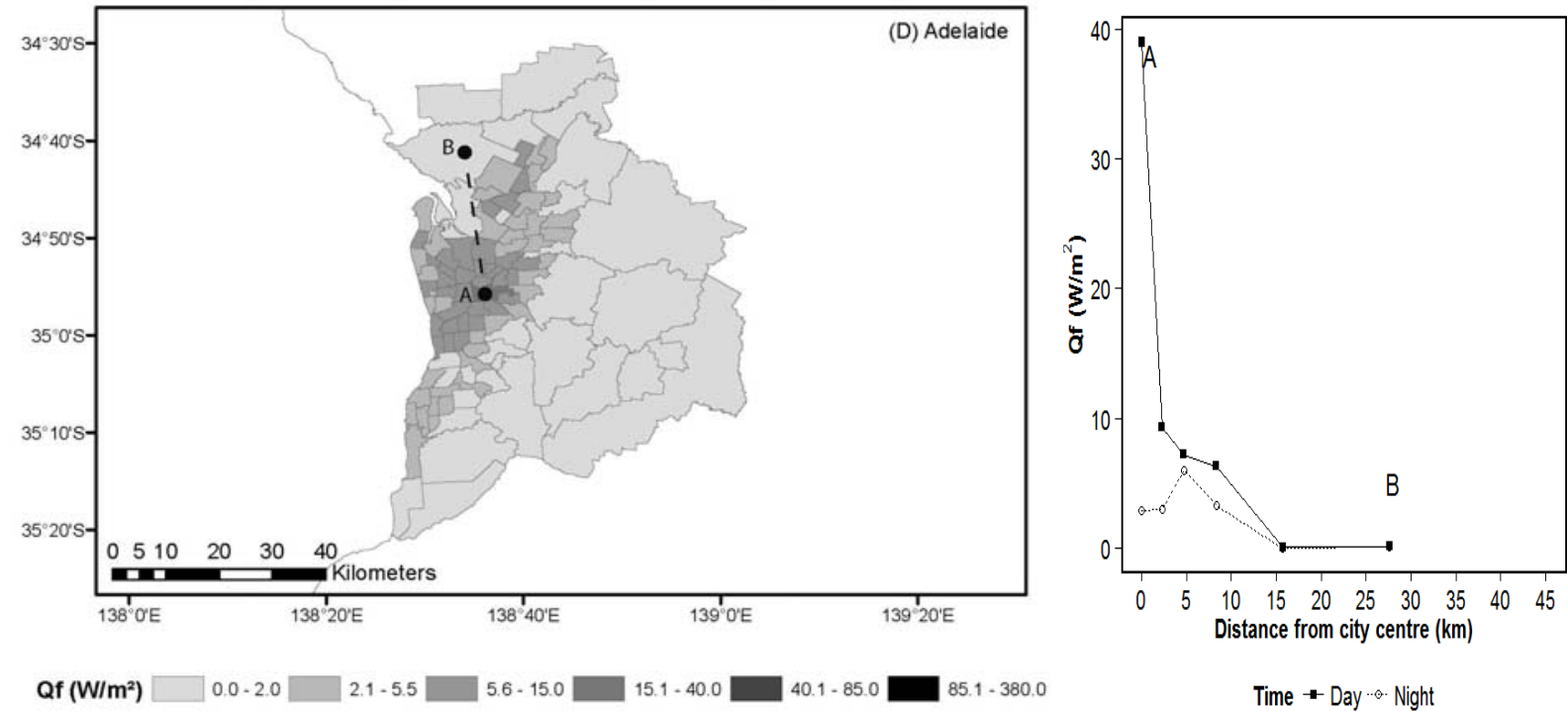

Figure 7 Brisbane (A), Sydney (B), Melbourne (C) and D) Adelaide annual average hourly anthropogenic heat emissions $\left(\mathrm{W} / \mathrm{m}^{2}\right)$ during the day $(0800-1600)$ for each Statistical Area level 2 census region. Max values Brisbane $261 \mathrm{~W} / \mathrm{m}^{2}$, Melbourne $376 \mathrm{~W} / \mathrm{m}^{2}$, Adelaide $39 \mathrm{~W} / \mathrm{m}^{2}$ and Sydney $256 \mathrm{~W} / \mathrm{m}^{2}$. Emissions are highest in the city centres, reflecting high working population densities. The graphs (right) are shown for transects (from A - B) from the city centre. Distance graph shows anthropogenic heat flux, $\mathrm{Q}_{\mathrm{f}}$, for selected SA2 regions of increasing distance from the city centre. Brisbane's heat flux decreases to $<5 \mathrm{~W} / \mathrm{m}^{2}$ at $20 \mathrm{~km}$ from the city centre, while Adelaide reached $5 \mathrm{~W} / \mathrm{m}^{2}$ at $15 \mathrm{~km}$. Sydney and Melbourne reach $10 \mathrm{~W} / \mathrm{m}^{2}$ at $36 \mathrm{~km}$ and $11 \mathrm{~km}$ from the city centre respectively. Detailed data for all regions are included in Supplementary Material.

Anthropogenic heat flux decreased with distance from the city centre, particularly during the day (Figure 7). During the night, the heat flux was overall lower and there was less difference in heat flux between the city centre and surrounding suburbs. At night, the CBD in all cities, except Melbourne, no longer had the highest heat flux, and the highest heat flux instead occurred in the surrounding suburbs. This reduction in heat flux was due to the low resident populations in the CBD areas. The highest night-time heat flux of $32 \mathrm{~W} / \mathrm{m}^{2}$ was in Sydney. The large increase in anthropogenic heat flux during the day was influenced by the high working population density. The average daytime and night-time anthropogenic heat emissions for each SA2 region are available in the Supplementary Material.

The contribution of each heat source to overall anthropogenic heat was similar in each city (Figure 8). Vehicles contributed between $42-46$ per cent, electricity $25-28$ per cent, gas $24-26$ per cent and human heat release $4-5$ per cent. The diurnal profile for all cities is dominated by vehicle emissions, coinciding with the peaks of morning and evening traffic. Building emissions, which includes electricity and gas, and emissions from human metabolism, have relatively little diurnal variation when compared to the range for vehicle emissions. In summer, electricity consumption contributed slightly more to emissions, while the contribution from heating fuels decreased, and vice versa in winter. 


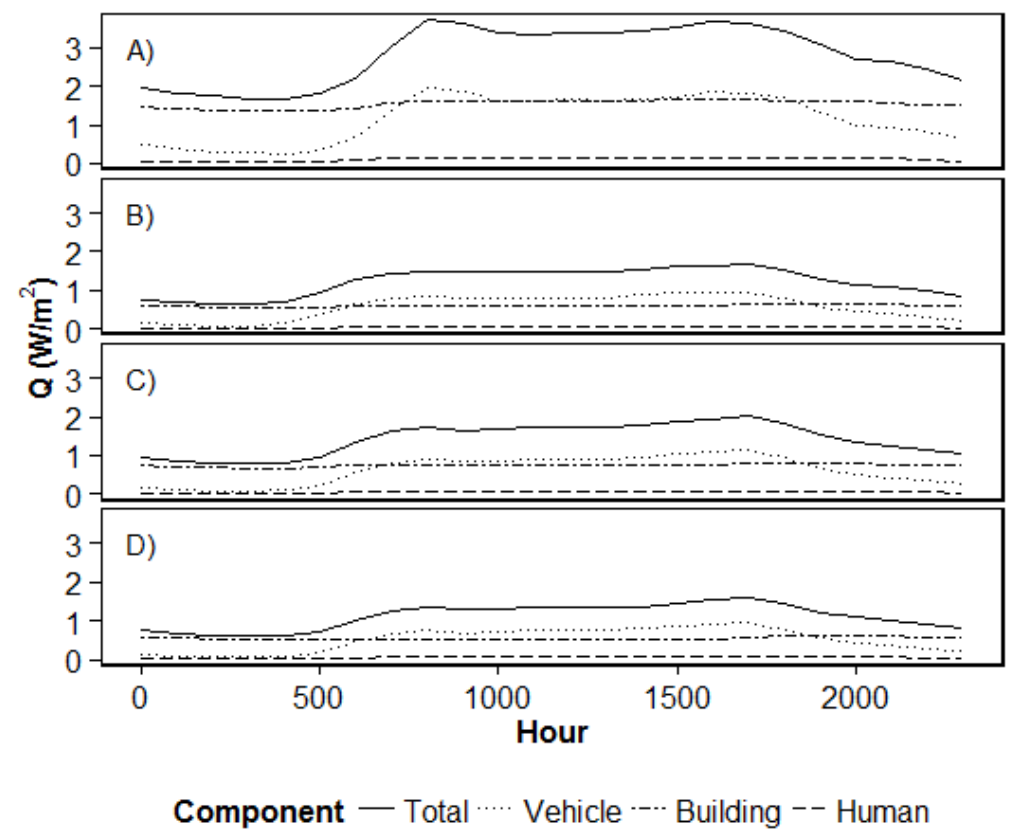

Figure 8 Contribution of each component: vehicles, building (electricity and gas) and human metabolism, totalling $\mathrm{Q}_{\mathrm{f}}$ throughout the day for each city. $\mathrm{A}=$ Brisbane, $\mathrm{B}=$ Sydney, $\mathrm{C}=$ Melbourne, $\mathrm{D}=$ Adelaide. $\mathrm{Q}_{\mathrm{f}}$ values are non-seasonal city-wide averages.

\section{Discussion}

Anthropogenic heat contributes to urban heat stress through the heat island, but is often neglected in urban climate studies due to a lack of estimates (Quah and Roth, 2012, Sailor, 2011). Previous work has shown that anthropogenic heat can increase urban temperatures by between $1-3^{\circ} \mathrm{C}$ (Bohnenstengel et al., 2014, Kimura and Takahashi, 1991, Fan and Sailor, 2005, Sailor, 2011). Excluding anthropogenic heat therefore risks underestimating urban temperatures and the associated risk of heat stress.

We found a large spatial variation in the anthropogenic heat emissions within each city associated with spatial variation in population density. As expected, the city centres and the high-density statistical areas had the highest emissions, particularly during the day. Average daytime emissions in the Melbourne CBD exceeded $300 \mathrm{~W} / \mathrm{m}^{2}$, while the emissions in the surrounding suburbs were less than $100 \mathrm{~W} / \mathrm{m}^{2}$. The Brisbane and Sydney CBDs had emissions greater than $200 \mathrm{~W} / \mathrm{m}^{2}$, which decreased to less than $100 \mathrm{~W} / \mathrm{m}^{2} 3 \mathrm{~km}$ from the CBD. This large variation across the city has also been observed in London (Bohnenstengel et al., 2014). In London, hourly anthropogenic heat flux in the city centre exceeded $400 \mathrm{~W} / \mathrm{m}^{2}$, while at the city fringes it was only $60 \mathrm{~W} / \mathrm{m}^{2}$ (Bohnenstengel et al., 2014). The variation in anthropogenic heat emissions with population is also consistent with other studies (Quah and Roth, 2012, Oke, 1988).

Anthropogenic emissions varied seasonally in each city. Sydney, Melbourne and Adelaide, with their temperate climates, had higher emissions in winter, due to higher gas and electricity usage. In contrast, emissions in sub-tropical Brisbane were higher in summer due to electricity usage, possibly due to increased use of air-conditioning. These differences are reflected in the differences in the number of heating and cooling degree days among the four cities (Table 1). Brisbane has 996 more cooling degree days than heating, while Sydney, Melbourne and Adelaide have more heating degree days than cooling (Guan, 2009). Most previous work has found higher anthropogenic heat emissions in winter, particularly in temperate climates (Quah and Roth, 2012, Sailor and Lu, 2004). There have been a small number of studies on cities with tropical climates. Work by Quah and Roth (2012) for Singapore found emissions were higher in summer, which they linked to the need for cooling. This is consistent with the results found for Brisbane. 
The contribution of each component (i.e., vehicle, building and human metabolism) to overall anthropogenic heat flux was similar to results for other cities. Vehicle emissions account for 42 - 46 per cent of total anthropogenic heat flux, while human metabolism accounted for $4-5$ per cent. This is similar to results for other cities, where vehicles contribute between 47 - 62 per cent in Chicago, Atlanta, Los Angeles, San Francisco, Salt Lake City and Philadelphia and 51 per cent in São Paulo, while human metabolism contributes 2 - 3 per cent in the previously listed American cities and 8 per cent in São Paulo (Sailor and Lu, 2004, Ferreira et al., 2011, Sailor et al., 2015). In South Korea, vehicle emissions are lower, accounting for between 25 - 40 per cent of total emissions (Lee et al., 2009). The main difference between this study and others is heating fuel usage. In colder climates, heating fuel can contribute up to 57 per cent of emissions in winter (Sailor and $\mathrm{Lu}, 2004$ ), whereas in the Australian cities studied here the variation between summer and winter was considerably smaller, accounting for less than 27 per cent of the total heat flux. In warmer climates, such as in São Paulo, Brazil, there is little seasonal variation in emissions from buildings (electricity and gas), which remains at around 40 per cent all year (Ferreira et al., 2011).

Despite having a higher population than both Brisbane and Melbourne, Sydney had lower daily heat flux. Sydney had slightly higher overall electricity use than Brisbane and Melbourne, but lower car travel. As vehicle emissions contributed nearly twice as much to total anthropogenic heat as electricity use, Sydney's lower car travel had a larger impact on anthropogenic heat flux than the higher electricity use. The maximum hourly anthropogenic heat flux was also lower in Sydney as compared to Brisbane and Melbourne, while the Sydney CBD was also almost twice as large $\left(4.3 \mathrm{~km}^{2}\right)$ as those for Brisbane and Melbourne (2.2 and $2.4 \mathrm{~km}^{2}$ ). The working population was more densely located in Melbourne and Brisbane than in Sydney. The most densely populated region during the day in Sydney, Haymarket - The Rocks, had a lower population density than the most densely populated region in Melbourne, the Melbourne CBD. The surrounding SA2 regions in Sydney however had a higher population density than the regions surrounding the Melbourne CBD. This suggests the working population is spread out over more SA2 regions in Sydney than in Melbourne. This is reflected in the anthropogenic heat flux of the SA2 regions surrounding the city centre, which reached $60 \mathrm{~W} / \mathrm{m}^{2}$ for Melbourne, but over $100 \mathrm{~W} / \mathrm{m}^{2}$ in Sydney. Sydney's lower maximum anthropogenic heat flux is most likely related to the lower per capita car travel compared to Melbourne and Brisbane, and the more dispersed working population.

Comparing the results of this study to other studies in Australia is difficult due to differences in city-boundaries and spatial scale. Sailor et al. (2015), using an equation based on American cities, found a maximum summer value of $24.48 \mathrm{~W} / \mathrm{m}^{2}$ for Sydney, and a maximum winter value of $21.81 \mathrm{~W} / \mathrm{m}^{2}$. This is much higher than the city-wide average calculated here, but lower than the values found in the city-centre. Given that study provides little information on which parts of Sydney this calculation applies to, a comparison is difficult. The results of a study by Khan and Simpson (2001) for Brisbane are also difficult to compare due to differences in urban, rural and suburban land cover categories, and a lack of detail on how these categories were defined. Coutts et al. (2008) measured anthropogenic heat in Preston, north of Melbourne, as being between $9-12 \mathrm{~W} / \mathrm{m}^{2}$. In our study, the values for the Preston SA2 region varied between $5-14 \mathrm{~W} / \mathrm{m}^{2}$, with an average of $9.9 \mathrm{~W} / \mathrm{m}^{2}$, which is comparable to Coutts et al. (2008).

The overall city wide averages for the Australian cities are low (Table 3), particularly when compared to higher density cities in Singapore (Quah and Roth, 2012), Brazil (Ferreira et al., 2011), Korea (Lee et al., 2009), and North America (Sailor and Lu, 2004). The average anthropogenic heat flux for American cities varied between $5-70 \mathrm{~W} / \mathrm{m}^{2}$, while for Australian cities the average was between 1- $4 \mathrm{~W} / \mathrm{m}^{2}$ (Sailor and Lu, 2004). For Sydney, Melbourne and Adelaide, there are over $30 \mathrm{SA} 2$ regions each with emissions $<2 \mathrm{~W} / \mathrm{m}^{2}$. In an area-weighted average these large low-emission areas bring down the city-wide average. Examining these areas using recent aerial photography reveals that these areas are more rural than urban (e.g., Yarra Valley in Melbourne, Redlands in Brisbane, Blue Mountains in Sydney). Unfortunately, for those studies that report only city-wide values, it is not always clear how the limits of the city were defined. Using smaller limits to the study area would have increased the results for the city-wide average. Calculating anthropogenic heat separately for each SA2 census region makes it clear in this case where the boundaries of the city were drawn, and how anthropogenic heat emissions vary spatially across the city.

While the city-wide averages were comparatively low for Australian cities, the peak values were comparable to those reached in other cities. The peak value for Melbourne $\left(>400 \mathrm{~W} / \mathrm{m}^{2}\right)$ is comparable to values for the centre of London which range between $400-600 \mathrm{~W} / \mathrm{m}^{2}$, and the peak values for Tokyo, which range between $400-1590 \mathrm{~W} / \mathrm{m}^{2} \mathrm{depending}$ on season (Bohnenstengel et al., 2014, Ichinose et al., 1999). In these cities, anthropogenic heat increases the urban heat island by $1-1.5^{\circ} \mathrm{C}$ (Sailor, 2011, Bohnenstengel et al., 2014). The similarities between the Melbourne, London and sum- 
mer-time Tokyo anthropogenic heat fluxes indicate that anthropogenic heat is an important contributor to Melbourne urban temperatures, particularly in the city centre.

\begin{tabular}{llllll}
\hline Year & City & $\begin{array}{l}\text { Pop size } \\
(\text { millions })\end{array}$ & $\begin{array}{l}\text { Pop den- } \\
\text { sity } \\
\left(\mathrm{km}^{2}\right)\end{array}$ & $\begin{array}{l}\text { Anthropogenic heat } \\
\left(\mathrm{W} / \mathrm{m}^{2}\right)\end{array}$ & Source \\
\hline 2004 & Atlanta, USA & 0.4 & 1,830 & $5-15$ & Sailor and Lu (2004) \\
2004 & Chicago, USA & 2.9 & 8,280 & $10-75$ & Sailor and Lu (2004) \\
2004 & Los Angeles, USA & 3.7 & 5,570 & $10-35$ & Sailor and Lu (2004) \\
2004 & Philadelphia, USA & 1.5 & 8,760 & $10-70$ & Sailor and Lu (2004) \\
$2008-2009$ & Singapore & 5 & $40-120$ for com- & Quah and Roth \\
& & & 7,000 & $7-15$ for residential & (2012) \\
$2004-2007$ & Sao Paulo, Brazil & 10.8 & 12,740 & $5-20$ & Ferreira et al. (2011) \\
2002 & Seoul, Korea & 10.3 & 17,000 & 55 & Lee et al. (2009) \\
2002 & Incheon, Korea & 2.6 & 2,650 & 53 & Lee et al. (2009) \\
& Gyeonggi, Korea & 10.4 & 1,021 & 28 & Lee et al. (2009) \\
\hline
\end{tabular}

Table 3 City-wide average anthropogenic heat emissions estimated from previous studies. The results for these studies are generally much higher than the city-wide average for Australian cities calculated here of between 1 $4 \mathrm{~W} / \mathrm{m}^{2}$. Where population density was reported for day and night, the daytime value was used. Seoul had an average population density of 17,000 people $/ \mathrm{km}^{2}$, but reached a max of 55, 697 people $/ \mathrm{km}^{2}$ (Lee et al., 2009).

The anthropogenic heat values presented here were calculated based on 2011 population census data. Since then the study cities have increased in population; Brisbane and Melbourne have grown by over 300,000 people, and Sydney by over 200,000 people (Australian Bureau of Statistics, 2015a). These trends are expected to continue into the future. In the next twenty years, Brisbane is expected to grow by over 800,000 people (Brisbane City Council, 2013), Sydney by 1,600,000 people (NSW Department of Planning and Environment, 2014), and the Melbourne CBD population is expected to grow by 83 per cent (City of Melbourne, 2016). As the population increases, the anthropogenic heat release should also increase if per capita vehicle and electricity use does not change. As the increased population will come with increased density (Brisbane City Council, 2013, City of Melbourne, 2016) and not just expansion of the city, the maximum anthropogenic heat release is expected to increase. The increase in maximum anthropogenic heat release would further increase urban temperatures and the heat stress faced by urban residents in the city centres, which will also be exacerbated by climate change.

It is our intention that the $\mathrm{Q}_{\mathrm{f}}$ values calculated in this study, and provided in the Supplementary Material, will be used in future urban climate studies for Australia. As the spatial scale of the $\mathrm{Q}_{\mathrm{f}}$ values varies within each city, due to variation in the size of the SA2 regions, their inclusion in an urban climate model may require sampling to a uniform grid that corresponds to the grid size of the climate model. Alternatively, if a model uses multiple urban land use categories, such as residential, or high-density, modelling studies may select the SA2 regions that best correspond to their urban categories, and use an average $\mathrm{Q}_{\mathrm{f}}$ value from those regions. 


\section{Approach and limitations}

In our study, the calculation of hourly profiles was limited due to lack of data, and the inherent limitations of the inventory method. The diurnal variation was very similar for all cities. This is due to these cities relying on the hourly winter gas profile of Melbourne, and Adelaide using Melbourne's hourly traffic profile. Further limitations include assuming that all workers arrive at work at the same time, and excluding shoppers and tourists (Quah and Roth, 2012, Medina et al., 2011). As well as the data limitations, the inventory method does not account for the lag between energy use and heat release in buildings, which introduces errors into the hourly estimation of anthropogenic heat (Sailor, 2011).

There can be significant differences between energy consumption and heat release in buildings (Dhakal et al., 2003, Dhakal et al., 2004, Sailor, 2011). The diurnal variation in heat discharge varies based on building type, type of heating and cooling system, location of air-conditioners in the building, and external air temperature (Dhakal et al., 2003, Dhakal et al., 2004, Sailor, 2011). Studies in Tokyo have found that most buildings store heat during the day, and release it in the late afternoon or evening, and thus methods that ignore the time lag would over-estimate the day time heat release, and underestimate night time heat release (Dhakal et al., 2003). In summer, the heat release from buildings can be higher than expected from energy consumption alone due to solar heating (Sailor, 2011). Methods that assume energy consumption is the same as heat release can have large errors in the timing of emissions which are not easily corrected (Sailor, 2011). Despite this, inventory methods are still common as they are easy to apply to widespread areas, and the difficulty in acquiring the data to estimate building heat release (Sailor, 2011, Dhakal et al., 2003).

The assumptions related to the time of work, gas consumption, and building heat release have introduced potential errors into the timing of anthropogenic heat release. Assumptions relating to building environmental loads, and the use of state data for city calculations, have also introduced errors into the magnitude of anthropogenic heat emissions. Using aggregate state data for city calculations could potentially lead to an over or under-estimation of anthropogenic heat if the per capita energy use of urban residents is different than rural residents. State-level industrial electricity and gas usage was included in the calculations, which assumes that industry does not vary throughout the state. Mining and agricultural energy usage were excluded as they mostly occur outside cities. Again, this could lead to over or under-estimating anthropogenic heat. These assumptions were unavoidable given the data available for the study cities, and are common to all inventory approaches (Sailor, 2011). Despite the limitations to the inventory method, it is the most common way of calculating anthropogenic heat emissions (Sailor, 2011).

\section{Conclusion}

We estimated spatial, diurnal and seasonal profiles of anthropogenic heat flux for four Australian capital cities. We found that Sydney, Melbourne and Adelaide have higher winter than summer anthropogenic heat flux, while Brisbane has higher overall summer heat flux. This is due to differences in gas and electricity usage, which are related to differences in climate and the need for heating in winter and cooling in summer. We also found a large spatial variation in anthropogenic heat flux, with emissions decreasing rapidly with distance from the city centre. There was a large diurnal variation in anthropogenic heat flux due to hourly variation in population densities, car travel, electricity and gas usage. During the day there was a large increase in anthropogenic emissions in the city centre due to the influx of workers, while at night-time there was less spatial variation in anthropogenic heat. The Melbourne and Sydney CBDs had anthropogenic emissions above $300 \mathrm{~W} / \mathrm{m}^{2}$, while the Brisbane CBD had emissions above and $200 \mathrm{~W} / \mathrm{m}^{2}$, which may affect urban temperatures in these areas.

Anthropogenic heat contributes up to $3^{\circ} \mathrm{C}$ to the urban heat island, which increases urban heat stress (Sailor, 2011, Kimura and Takahashi, 1991, Luber and McGeehin, 2008). Heat stress is a serious public health concern in Australia, and heatwaves have been responsible for more deaths than any other extreme weather event (Coates, 1996, Hanna et al., 2011). Heat stress will become more important as temperatures rise due to climate change, and an aging and increasingly urban population (Hughes et al., 2016). The anthropogenic heat emissions in the centre of Melbourne are comparable to the peak London and Tokyo summer values of around $400 \mathrm{~W} / \mathrm{m}^{2}$, though much lower than the winter Tokyo values of $1590 \mathrm{~W} / \mathrm{m}^{2}$ (Bohnenstengel et al., 2014, Sailor, 2011). In Tokyo, the summer anthropogenic heat emissions are enough to increase urban temperatures by $1-1.5^{\circ} \mathrm{C}$ (Sailor, 2011). Given this, anthropogenic heating in Melbourne, Sydney and Brisbane could potentially be an important contributor to the urban heat island and heat stress in the central parts of the city. Effective adaptation to the increasing threats to urban health from climate change and the urban heat island requires understanding the future urban climate (Luber and McGeehin, 2008, Medina-Ramón and Schwartz, 2007, Kusaka et al., 2012, Fischer 
et al., 2012). This study assists in this effort by estimating current anthropogenic heat values for use in urban climate studies in four major Australian cities.

\section{Acknowledgements}

We are grateful to LM and WG, and two anonymous reviewers, for providing constructive feedback on this article. We would also like to thank the VicRoads, Brisbane City Council and the Roads and Maritime Service for providing traffic data.

\section{References}

Allen, L., Lindberg, F. and Grimmond, C. S. B. 2011. Global to city scale urban anthropogenic heat flux: model and variability. International Journal of Climatology, 31, 1990-2005.

Argueso, D., Evans, J., Fita, L. and Bormann, K. 2014. Temperature response to future urbanization and climate change. Climate Dynamics, 42, 2183-2199.

Australian Bureau of Statistics 2011a. Australian Statistical Geography Standard (ASGS): Volume 1 - Main Structure and Greater Capital City Statistical Areas. Australian Bureau of Statistics.

Australian Bureau of Statistics 2011b. Census of Population and Housing. Canberra.

Australian Bureau of Statistics 2011c. Statistical Area Level 2 (SA2) ASGS Ed 2011 Digital Boundaires in ESRI Shapefile Format.

Australian Bureau of Statistics 2012a. 1367.0 State and Territory Statistical Indicators, 2012. Canberra.

Australian Bureau of Statistics 2012b. 9208.0 Survey of Motor Vehicle Use, Australia, 12 months ended 30 June 2012. Canberra.

Australian Bureau of Statistics. 2013a. 3218.0 - Regional Population Growth, Australia, 2011-12 [Online]. Canberra. Available:http://www.abs.gov.au/AUSSTATS/abs@.nsf/allprimarymainfeatures/776E5119027E0895CA257BD60010 D0FC?opendocument [Accessed 20/04/16].

Australian Bureau of Statistics. 2013b. Population Projections, Australia, 2012 (base) to 2101 [Online]. Available: http://www.abs.gov.au/AUSSTATS/abs@.nsf/mf/3222.0 [Accessed 4/08/2015].

Australian Bureau of Statistics. 2015a. 3218.0 - Regional Population Growth, Australia, 2014-15 [Online]. Canberra. Available:http://www.abs.gov.au/ausstats/abs@.nsf/Latestproducts/3218.0Main\%20Features302014-

15?opendocument\&tabname=Summary\&prodno=3218.0\&issue=2014-15\&num=\&view= [Accessed 20/04/16].

Australian Bureau of Statistics 2015b. 4604.0 Energy Account, Australia, 2012-2013.

Australian Energy Market Operator. 2015a. Actual Flow.

Australian Energy Market Operator. 2015b. Aggregated Price \& Demand : 2011 - 2015.

Bi, P., Willams, S., Loughnan, M., Lloyd, G., Hansen, A., Kjellstrom, T., Dear, K. and Saniotis, A. 2011. The Effects of Extreme Heat on Human Mortality and Morbidity in Australia: Implications for Public Health. Asia-Pacific Journal of Public Health, 23, 27S-36S.

Black, M.T., Karoly, D.J. and King, A.D. 2015. The Contribution of Anthropogenic Forcing to the Adelaide and Melbourne, Australia, Heat Waves of January 2014. Bulletin of the American Meteorological Society, 96, S145-S148.

Bohnenstengel, S.I., Hamilton, I., Davies, M. and Belcher, S.E. 2014. Impact of anthropogenic heat emissions on London's temperatures. Quarterly Journal of the Royal Meteorological Society, 140, 687-698.

Brisbane City Council. 2013. Brisbane Vision 2031. Brisbane.

Brisbane City Council. 2015. 30 Min Volumes for Ann and Edward St, Brisbane. Brisbane City Council.

Bureau of Meteorology. 2012. Climate classification maps [Online]. Australian Government. Available: http://www.bom.gov.au/jsp/ncc/climate_averages/climate-classifications/index.jsp?maptype=seasb\#maps [Accessed 15/02/16].

Bureau of Meteorology. 2016a. Summary Statistics ADELAIDE [Online]. Australian Government. Available: http://www.bom.gov.au/climate/averages/tables/cw_023090.shtml [Accessed 15/02/16].

Bureau of Meteorology. 2016b. Summary statistics BRISBANE AERO [Online]. Australian Government. Available: http://www.bom.gov.au/climate/averages/tables/cw_040223.shtml [Accessed 15/02/16].

Bureau of Meteorology. 2016c. Summary statistics MELBOURNE AIRPORT [Online]. Available: http://www.bom.gov.au/climate/averages/tables/cw_086282.shtml [Accessed 15/02/16].

Bureau of Reseources and Energy Economics. 2014a. 2014 Australian Energy Update. Australian Government.

Bureau of Reseources and Energy Economics. 2014b. Guide to the Australian Energy Statistics. Australian Government. 
Bureau of Transport and Regional Economics. 2007. Estimating urban traffic and congestion cost trends for Australian cities. Canberra.

City of Melbourne. 2016. Melbourne (CBD) [Online]. Melbourne: Geographia. Available: http://melbournepopulation.geografia.com.au/areas/CLSA01 [Accessed 20/04/16].

Coates, L. An overview of fatalities from some natural hazards in Australia. Proceedings of NDR96 Conference on Natural Disaster Reduction, 1996 Gold Coast, Australia.

Couttes, A.M., Beringer, J. and Tapper, N.J. 2007. Impact of Increasing Urban Density on Local Climate: Spatial and Temporal Variations in the Surface Energy Balance in Melbourne, Australia. Journal of Applied Meteorology and Climatology, 46, 477-480,482-493.

Couttes, A.M., Beringer, J. and Tapper, N.J. 2008. Investigating the climatic impact of urban planning strategies through the use of regional climate modelling: a case study for Melbourne, Australia. International Journal of Climatology, 28, 1943-1957.

Cowan, T., Purich, A., Perkins, S., Pezza, A., Boschat, G. and Sadler, K. 2014. More Frequent, Longer, and Hotter Heat Waves for Australia in the Twenty-First Century. Journal of Climate, 27, 5851-5871.

De Silva, H. and Lightfoot, A. 2010. Commuting to work by private vehicle in Melbourne: Trends and policy implications. Australasian Transport Research Forum 2010 Canberra, Australia.

Department Of Infrastructure And Transport 2013. State of Australian Cities 2013: Brisbane.

Dhakal, S., Hanaki, K. and Hiramatsu, A. 2003. Estimation of heat discharges by residential buildings in Tokyo. Energy Conversion and Management, 44, 1487-1499.

Dhakal, S., Hanaki, K. and Hiramatsu, A. 2004. Heat discharges from an office building in Tokyo using DOE-2. Energy Conversion and Management, 45, 1107-1118.

Fan, H. and Sailor, D. J. 2005. Modeling the impacts of anthropogenic heating on the urban climate of Philadelphia: A comparison of implementations in two PBL schemes. Atmospheric Environment, 39, 73-84.

Ferreira, M., De Oliveira, A. and Soares, J. 2011. Anthropogenic heat in the city of São Paulo, Brazil. Theoretical and Applied Climatology, 104, 43-56.

Fischer, E. M., Oleson, K. W. and Lawrence, D. M. 2012. Contrasting urban and rural heat stress responses to climate change. Geophysical Research Letters, 39, L03705.

Guan, L. 2009. Implication of global warming on air-conditioned office buildings in Australia. Building Research \& Information, 37, 43-54.

Hajat, S., O'Connor, M. and Kosatsky, T. 2010. Health effects of hot weather: from awareness of risk factors to effective health protection. The Lancet, 375, 856-863.

Hallenbeck, M., Rice, M., Smith, B., Cornell-Martinez, C. and Wilkinson, J. 1997. Vehicle Volume Distribution by Classification. Seattle: Washington State Transportation Center.

Hanna, E. G., Kjellstrom, T., Bennett, C. and Dear, K. 2011. Climate Change and Rising Heat: Population Health Implications for Working People in Australia. Asia-Pacific Journal of Public Health, 23, 14S-26S.

Hondula, D. M. and Barnett, A. G. 2014. Heat-Related Morbidity in Brisbane, Australia: Spatial Variation and Area-Level Predictors. Environmental Health Perspectives, 122, 831-836.

Hughes, L., Hanna, E. and Fenwick, J. 2016. The Silent Killer: Climate Change and The Health Impacts of Extreme Heat. Climate Council of Australia.

Ichinose, T., Shimodozono, K. and Hanaki, K. 1999. Impact of anthropogenic heat on urban climate in Tokyo. Atmospheric Environment, 33, 3897-3909.

Keay, K. and Simmonds, I. 2005. The association of rainfall and other weather variables with road traffic volume in Melbourne, Australia. Accident Analysis \& Prevention, 37, 109-124.

Khan, S. M. and Simpson, R. W. 2001. Effect Of A Heat Island On The Meteorology Of A Complex Urban Airshed. Boundary-Layer Meteorology, 100, 487-506.

Kimura, F. and Takahashi, S. 1991. The effects of land-use and anthropogenic heating on the surface temperature in the Tokyo Metropolitan area: A numerical experiment. Atmospheric Environment. Part B. Urban Atmosphere, 25, $155-164$.

Kusaka, H., Hara, M. and Takane, Y. 2012. Urban Climate Projection by the WRF Model at 3-km Horizontal Grid Increment: Dynamical Downscaling and Predicting Heat Stress in the 2070's August for Tokyo, Osaka, and Nagoya Metropolises. Journal of the Meteorological Society of Japan. Ser. II, 90B, 47-63.

Laaidi, K., Zeghnoun, A., Dousset, B., Bretin, P., Vandentorren, S., Giraudet, E. and Beaudeau, P. 2012. The Impact of Heat Islands on Mortality in Paris during the August 2003 Heat Wave. Environmental Health Perspectives, 120, 254259. 
Lee, S. H., Song, C. K., Baik, J. J. and Park, S. U. 2009. Estimation of anthropogenic heat emission in the Gyeong-In region of Korea. Theoretical and Applied Climatology, 96, 291-303.

Luber, G. and MCGeehin, M. 2008. Climate Change and Extreme Heat Events. American Journal of Preventive Medicine, 35, 429-435.

MCGeehin, M. A. and Mirabelli, M. 2001. The Potential Impacts of Climate Variability and Change on TemperatureRelated Morbidity and Mortality in the United States. Environmental health perspectives, 109, 185-189.

Medina-Ramón, M. and Schwartz, J. 2007. Temperature, Temperature Extremes, and Mortality: A Study of Acclimatisation and Effect Modification in 50 US Cities. Occupational and Environmental Medicine, 64, 827-833.

Medina, R., Cova, T. and Kobayashi, T. 2011. Visualizing Diurnal Population Change in Urban Areas for Emergency Management. The Professional Geographer, 63, 113-130.

Menut, L., Goussebaile, A., Bessagnet, B., Khvorostiyanov, D. and Ung, A. 2012. Impact of realistic hourly emissions profiles on air pollutants concentrations modelled with CHIMERE. Atmospheric Environment, 49, $233-244$.

Milojevic, A., Wilkinson, P., Armstrong, B., Davis, M., Mavrogianni, A., Bohnenstengel, S. and Belcher, S. 2011. Impact of London's Urban Heat Island on Heat-related Mortality. EPIDEMIOLOGY, 22, S182-S183.

NSW Department of Planning and Environment 2014. A Plan for Growing Sydney. NSW Government.

Oke, T.R. 1988. The urban energy balance. Progress in Physical Geography, 12, 471-508.

Palmer, G. 2012. Does energy efficiency reduce emissions and peak demand? A case study of 50 years of space heating in melbourne. Sustainability, 4, 1525-1560.

Peel, M.C., Finlayson, B.L. and MCMahon, T.A. 2007. Updated world map of the Köppen-Geiger climate classification. Hydrol. Earth Syst. Sci., 11, 1633-1644.

Quah, A.K.L. and Roth, M. 2012. Diurnal and weekly variation of anthropogenic heat emissions in a tropical city, Singapore. Atmospheric Environment, 46, 92-103.

R Core Team 2015. R: A language and environment for statistical computing. Austria: Vienna: R Foundation for Statistical Computing.

Roads and Maritime Service 2015. Sydney traffic count data. Sydney: NSW Government.

Sailor, D.J. 2011. A review of methods for estimating anthropogenic heat and moisture emissions in the urban environment. International Journal of Climatology, 31, 189-199.

Sailor, D.J., Georgescu, M., Milne, J.M. and Hart, M. A. 2015. Development of a national anthropogenic heating database with an extrapolation for international cities. Atmospheric Environment, 118, 7-18.

Sailor, D.J. and Lu, L. 2004. A top-down methodology for developing diurnal and seasonal anthropogenic heating profiles for urban areas. Atmospheric Environment, 38, 2737-2748.

Sharifi, E., Sivam, A. and Boland, J. 2015. Resilience to heat in public space: a case study of Adelaide, South Australia. Journal of Environmental Planning and Management, 1-22.

Smith, C., Lindley, S. and Levermore, G. 2009. Estimating spatial and temporal patterns of urban anthropogenic heat fluxes for UK cities: The case of Manchester. Theoretical and Applied Climatology, 98, 19-35.

Taha, H. 1997. Urban climates and heat islands: albedo, evapotranspiration, and anthropogenic heat. Energy \& Buildings, 25, 99-103.

United Nations 2014. World Urbanization Prospects: The 2014 Revision - Highlights. New York: United Nations.

Vicroads 2015. Typical Hourly Traffic Volume. Government of Victoria.

Wienert, U. and Kuttler, W. 2005. The dependence of the urban heat island intensity on latitude - A statistical approach. Meteorologische Zeitschrift, 14, 677-686. 